\title{
The Bacterial Load in the Nasal Mucosa of Chinese Patients
}

\author{
A. GRACE WARREN
}

\author{
Hay Ling Chau Leprosarium, Hong Kong
}

\begin{abstract}
In Chinese patients it is not possible to rely on the presence or absence of Myco. leprae in the nasal mucosa to confirm or deny a diagnosis of leprosy. Although the load of bacteria in the nose may be high in some untreated patients, during treatment it falls more rapidly there than elsewhere in the hody.
\end{abstract}

Examination of the nasal mucosa for bacterial load has been suggested as a means of diagnosis of leprosy and for the determination of the degree of infectivity. Browne (1966) found in Nigeria that the bacillary index (B.I.) of the nasal mucosa was frequently higher than that of the routine skin smears and that bacilli may persist in the nasal mucosa after the skin sites have become negative. Goodwin (1967) implied that examination of nasal smears was not a reliable means of diagnosis or for following the patient's progress. He correlated the level of the bacillary concentration in the nose with the type of leprosy.

Nasal smears have been examined in this institution. Hay Ling Chau, from time to time, but not regularly, since the procedure is not pleasant and we feel that the extra information that it provides is not enough to offset the discomfort it causes and the risk of losing the patient's future co-operation.

Checking our records, we have found 85 patients who have had nasal smears examined since Dr Stanley Browne checked the technique of our technician in 1967. All the smears were taken and examined by the same technician, who also does the routine skin smears. As well as taking smears from the nasal septum, as described by Browne (1966), he also examined swabs of the nasal mucosa in some patients. Attempts at examination of nose "blows" did not yield any useful information, as the bacillary load was always much lower than that in the nasal smears. The load in the nasal swab was also lower than that in the skin smear, but did show acid-fast bacteria which were occasionally of normal morphology.

The group included 49 patients whose nasal smears were examined within 4 weeks of starting regular anti-leprotic therapy. In this group there were 19 newly diagnosed patients with lepromatous-type leprosy whose skin smear B.I. varied from 5.3 to 2.0. There were also 4 lepromatous patients who had relapsed because of discontinuation of regular therapy. The highest morphological index (M.I.) was $30 \%$ (patient no. 2113), but in most cases the M.I. was between $2 \%$ and $10 \%$, and in 10 patients the skin M.I. was already $0 \%$. In most of the patients the nasal B.I. and M.I. were equal to, or slightly lower than, the skin smear, and the concentration of bacilli recovered from the nose fell at a rate similar to that for the skin. One patient (no. 2113) had a skin smear of 455455 (4.7), with a M.I. of 
$30 \%$ and a nasal B.I. of 6 , with $60 \%$ M.I., and a nasal mucosa swab also showed a B.I. of 2. 27 months later, the nasal B.I. was still 2, but the M.I. was $0 \%$ and all swabs were negative. After a further 3 months, all nasal smears were free from acid-fast organisms; by that time the skin smear was 3.2 and the patient's general progress was slow but satisfactory. In no patient examined was a negative skin smear found in the presence of a positive nasal smear.

Of the other patients examined on admission, there were 10 in the BL or near lepromatous groups. All except one showed a nasal M.I. of $0 \%$ initially, though several did have morphologically normal bacilli in their skin smears, and in one patient the skin smear M.I. was $30 \%$. The exception was a patient (no. 2107) who had been taking dapsone irregularly for years. On admission both skin and nasal M.I. were $20 \%$ and a nasal mucosa swab showed a B.I. of 3 . He was later given clofazimine (Lamprene, Geigy) for presumed dapsone resistance and acute neuritis.

Of the patients with BB-BT type leprosy, 13 showed negative nasal smears, though skin smears varied from 0.7 to $4.0 ; 3$ others had positive nasal smears. One patient (no. 1936) had a skin smear of 2.5 and a nasal B.I. of 3 , with an M.I. of $3 \%$. He developed an upgrading reaction, during which the bacillary load fell rapidly, though his leprosy may well have initially been of BL type.

The other patients were not examined within the first few weeks of commencing anti-leprosy treatment, but results of irregular examination of the nasal bacilli agreed in general with the findings in the main group. Since we cannot do serial examinations on negative patients to watch for early signs of bacterial relapse, we cannot make any statement about the time of reappearance of bacilli in the nose of relapsing patients. However, one patient (no. 1449) was re-admitted in April 1972, in relapse with skin smear showing a B.I. of 4.8 and M.I. of $10 \%$. Nasal smears were not done then. It was suspected that he was resistant to both dapsone and thiambutosine, since he had been taking treatment irregularly for some years. A biopsy specimen was taken for mouse-footpad sensitivity tests, and the patient was advised to take Lamprene. He refused this, and was given injectable dapsone on which he appeared to make slow progress for 4 months, his smear falling to B.I. 4.3 and M.I. 0\%, and then becoming stationary. His nasal smears were done in March 1973, and were all negative for acid-fast organisms.

In May 1973, the mouse-footpad test results indicated dapsone resistance. He still refuses to take Lamprene, saying he will wait until his skin smear shows definite deterioration. However, his last nasal smear in June 1973 was positive, with a B.I. of 2 but M.I. 0\%. The nasal mucosa swabs were negative. It may be that this patient is showing the first definite signs of resistance by increase in the nasal bacterial load and a careful watch will be kept on him.

\section{Conclusions}

In Chinese patients it is apparent that:

(1) The bacillary index of the nasal mucosa is similar to that of the skin in untreated patients with lepromatous type leprosy, but it becomes negative sooner; (2) the morphological index in the nose is equal to, or less than, that of the skin, and usually becomes negative before the M.I. of the skin becomes negative; (3) in patients with a greater immunological response, e.g. BB-BT type, the nasal mucosa is usually bacillary negative, unless a lesion occurs across the nose; and (4) nasal 
smears do little to help confirm the diagnosis of leprosy, and if this is the only site examined may well lead to an incorrect diagnosis, especially in the borderline groups of patients.

\section{References}

Browne, S. G. (1966). The value of nasal smears in lepromatous leprosy. Int. J. Lepr. 34 (1), 23-26.

Goodwin, C. S. (1967). The significance of Mycobacterium leprae in the nasal mucosa, with special reference to Chinese leprosy patients. Lepr. Rev. 38 (3), 181-188. 